\title{
Peripartum Hysterectomy and Analysis of Risk Factors
}

\author{
Basnet $\mathbf{P}^{1}$, Thakur A $\mathbf{A}^{\mathbf{1}}$, Agrawal A ${ }^{\mathbf{1}}$, Rai $\mathbf{R}^{\mathbf{1}}$, Shrestha $\mathbf{R}^{1}$ \\ ${ }^{1}$ Department of Obstetrics and Gynaecology, BPKIHS, Dharan
}

Received: 15-Feb-2017; Accepted: 30-Mar-2017

\begin{abstract}
Aims: To determine the incidence and risk factors of women undergoing peripartum hysterectomy at BPKIHS, Dharan.
Methods: A descriptive study was conducted for all women undergoing peripartum hysterectomy in two years from July 2012 to June 2014. Various maternal characteristics including demographic data, previous obstetric details, antepartum, intrapartum and postpartum data were collected and analysed.

Results: There were 29 cases of peripartum hysterectomy among 19,539 births in 2 yrs (1.48 per 1000 births). Indications for peripartum hysterectomy were uterine rupture $(65.5 \%)$, morbid adherence of the placenta $(13.8 \%)$ and uterine atony $(12.9 \%)$. Previous caesarean section was identified as independent risk factor with relative risk of 1.8 (95\% CI 1.3-2.5, p<0.003). Maternal morbidity was significant with febrile morbidity and urinary tract injury among the most common complications.
\end{abstract}

Conclusions: Uterine rupture causing severe haemorrhage was the commonest indication for peripartum hysterectomy. Timely intervention reduces the peripartum maternal and perinatal morbidity and mortality.

Keywords: peripartum hysterectomy, rupture uterus, emergency hysterectomy

DOI: http://dx.doi.org/10.3126/njog.v12i1.18981

\section{INTRODUCTION}

Peripartum hysterectomy is an emergency condition. It is defined as hysterectomy performed after vaginal delivery or at the time of cesarean birth, in situations where conservative measures do not control haemorrhage. It may be considered as a "near- miss" event which is defined as severe life threatening obstetrical complication necessitating urgent intervention in order to prevent likely death of the mother. ${ }^{1}$ Hysterectomy performed as a result of peripartum complications is associated with significant maternal morbidity and mortality, as well as excess healthcare expenditures related to prolonged hospitalization, need for care in an intensive care unit, use of blood products, and the potential for additional surgical procedures. ${ }^{2}$

In the past, the most common indications for emergency peripartum hysterectomy were uterine atony and uterine rupture. ${ }^{3,4}$ In the developed countries, the preventable indications such as uterine rupture and uterine atony are giving way to the nonpreventable indications such as abnormal placentation, whereas in the developing countries,

\section{CORRESPONDENCE}

Dr Pritha Basnet,

Department of Obstetrics and Gynaecology, BPKIHS, Dharan Cell\#: +977-9842351775,

Email: prithapep@yahoo.com these preventable indications are still prevalent. ${ }^{5}$ This is not only because of improved conservative management of uterine

atony ${ }^{6}$ and a reduced incidence of uterine rupture due to the extensive use of the lower uterine segment incision in preference to the upper uterine segment incision for caesarean section (CS) but also because of an actual increase in the incidence of the morbidly adherent placenta.

The purpose of this study was to analyse the incidence, indications, risk factors, and complications associated with peripartum hysterectomies performed at a tertiary care centre.

\section{METHODS}

This is a descriptive study of peripartum hysterectomy carried out at a tertiary care centre BPKIHS, Dharan, Nepal from July 2012- June2014. During the study period there were 29 cases of peripartum hysterectomy. The study was conducted after approval from the Institutional Ethical Review Board and consent was obtained in all the cases.

Peripartum hysterectomy was performed when all conservative measures have failed to achieve homeostasis in the setting of life-threatening hemorrhage involving both surgical and medical interventions such as fundal massage, bimanual uterine compression, use of blood products, administration of oxytocin and prostaglandins, 
uterine packing, compression sutures and selective ligation of the ascending uterine artery within 24 hours of delivery.

Only women who delivered after 28 weeks gestation and underwent hysterectomy for obstetric reasons were included in the study. Cases of peripartum hysterectomy performed outside and referred for intensive care or any complication were excluded from the study.

Maternal and neonatal characteristics such as age, parity, booking status, gestational age at delivery, oxytocin usage, induction of labour, previous caesarean delivery, previous uterine surgery, mode of delivery, live birth or intrauterine fetal death were recorded. The indication for surgery, type of hysterectomy, additional procedures, estimated blood loss, need for blood transfusion, intensive care facility, requirement of ventilator support, postoperative complications, duration of hospital stay were obtained. Maternal mortality if any was recorded in the proforma.

Post operative complications included febrile morbidity, urinary tract infection, respiratory tract infection, anemia, wound infection, sepsis, disseminated intravascular coagulation were recorded. Febrile morbidity was described as a body temperature $>38^{\circ} \mathrm{C}$ measured at least $24 \mathrm{~h}$ after the hysterectomy and repeated at least once.

All data were stored in Microsoft Excel format and analysed in SPSS version 11.5. Chi-square test was used for categorical data and Student's t-test was used for continuous data. A p-value of less than 0.05 was taken as significant.

\section{RESULTS}

There were 19,539 deliveries and 29 women had peripartum hysterectomy. This gave an incidence of 1.48 per 1000 deliveries. The mean maternal age was $26.78 \pm 5.14$ years. Only one pregnant women who underwent hysterectomy had antenatal checkup in the institution and the rest were unbooked $(96.50 \%)$. The majority of women were multiparous (65.6\%). There were four primipara (13.7\%) and six grandmultipara $(20.6 \%)$ who had conceived more than 5 times.

Mean gestational age at delivery was $37 \pm 2.33$ weeks. Majority of the women underwent laparotomy $(65.5 \%)$ for rupture uterus with baby in peritoneal cavity. Four women had vaginal delivery $(13.8 \%)$ and six had caesarean delivery (20.7\%). There were 10 cases of previous caesarean section, nine of them had previous one section (31\%) and only one of them had previous two caesarean sections.
The various indications for peripartum hysterectomy are described in Table 1. Rupture uterus was the most common indication (21/29) followed by morbidly adherent placenta and uterine atony. The cause for rupture uterus has been illustrated in Table 2 . Twenty four women underwent subtotal hysterectomy $(82.8 \%)$ and only five had total hysterectomy. Estimated blood loss ranged from 500-3500L $(1631 \pm 695 \mathrm{ml})$.

All women invariably required blood transfusion with a mean blood transfusion unit of $4.34 \pm 2.32$. All the women received perioperative antibiotics comprising of ceftriaxone and metronidazole. Twenty-eighty patients (96\%) were admitted in intensive care unit and 12 patients $(41.5 \%)$ required mechanical ventilator. Febrile morbidity was the most common (14 patients, 48\%) complication post operatively. The various other complications are illustrated in Figure 1. There were three cases $(10 \%)$ of maternal mortality. All mortality occurred in the immediate post operative period due to haemorrhagic shock. The mean duration of hospital stay after surgery was $9 \pm$ 5.1days.

There were seven live births and twenty two still birth (75\%) mostly due to delay in delivery due to obstructed labour or rupture uterus.

Table 1: Indication for Peripartum Hysterectomy

\begin{tabular}{|lcc|}
\hline Indications & Number(n) & Percentage(\%) \\
\hline Rupture uterus & 21 & 72.4 \\
$\begin{array}{l}\text { Morbidly } \\
\text { adherent Placenta }\end{array}$ & 4 & 13.8 \\
Uterine atony & 4 & 13.8 \\
\hline
\end{tabular}

Table 2: Causes for Rupture Uterus

\begin{tabular}{|lll|}
\hline Causes & Number(n) & Percentage(\%) \\
\hline Obstructed labour & 13 & 62 \\
Previous Caesarean & 8 & 38 \\
\hline
\end{tabular}

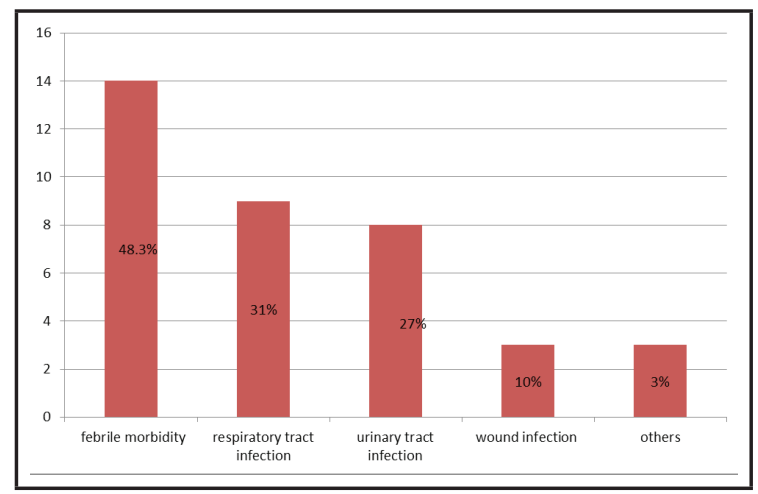

Figure 1: Post Operative Complications 


\section{DISCUSSION}

During the study period there were 19539 deliveries and 29 peripartum hysterectomy accounting for $1.48 / 1000$ births which is similar to the study done by Dan et al. ${ }^{6}$

In our study the mean maternal age was 26 years which is in contrast to many other studies where peripartum hysterectomy was done in women with mean maternal age $>30$ yrs. $^{8}$ This reflects the difference in the mean age of obstetric population at different places and countries and in developed countries the shift of maternal age towards elderly group is due to literacy and advancement in artificial reproductive technology.

Majority of the women were multiparous as observed in other studies. ${ }^{6}$ There are sparse data on booking status of women in the literature as $96.5 \%$ of pregnant women were unbooked in our study. It is obvious from the good antenatal care and health care system in the developed countries. This is quite relevant in our context which reflects lack of awareness of antenatal care, identification of high risk cases and timely referral.

In our study $65.5 \%$ of the women delivered by laparotomy which is obvious from the high rate of rupture uterus accounting for $72.4 \%$ of the total peripartum hysterectomy performed during the same period.

V Dandolu. et al in their study have quoted the lead indication for obstetrical hysterectomy in the past was atonic postpartum haemorrhage. The trend of peripartum hysterectomy has shifted towards abnormal placentation. Improved availability of uterotonic agents leading to the better control of bleeding and increased rate of risk factors for abnormal placentation such as prior Caesarean delivery have contributed to this shift., 10

Most of the women underwent subtotal hysterectomy in our study contributing to $82 \%$ of the overall peripartum hysterectomy performed during that period. In the past, total hysterectomy was the recommended surgical method in emergency peripartum hysterectomy due to the potential for cervical stump malignancy, need for regular cytology and other problems such as bleeding or discharge. ${ }^{11}$

Subtotal hysterectomy is usually preferred during peripartum hysterectomy because of technically easier, less time consuming procedure, less blood loss and less intraoperative and post operative complications. The proportion of women undergoing subtotal peripartum hysterectomy in our study is comparable to other studies accounting for 53$80 \%{ }^{12.13}$

The most common indication for peripartum hysterectomy in our study was rupture uterus $(72.4 \%)$ followed by morbidly adherent placenta (13.8\%) and uterine atony (13.8\%). Oguz et al in their study reported uterine rupture to be the most common indication for peripartum hysterectomy attributing to $35.3 \%$. The other indications were placenta accreta, uterine atony and haemorrhage. ${ }^{11}$ Chisara et al in their study reported placenta accrete (47.6\%) to be the most common indication for peripartum hysterectomy followed by uterine rupture $(28.6 \%)$ and uterine atony $(23.8 \%){ }^{5}$

Previous caesarean section was also identified as independent risk factor for peripartum hysterectomy in our study with a RR-1.8 (95\%CI 1.3-2.5) p< 0.003 . With rising caesarean section rates and marked reduction in the incidence of uterine rupture and atony due to proper antenatal and intrapartum care, placenta accreta has replaced uterine rupture and atony as the most common indication for emergency peripartum hysterectomy in the developed world.

The scenario in the developing country is still critical. When we further analysed the cause for rupture uterus, it was found that obstructed labour was the leading cause followed by previous caesarean section. Our centre being tertiary care centre and most of the women being unbooked, it again reflects our health care system, lack of senior health personnel at the primary and secondary care level, improper antepartum and intrapartum management and delay in identification of high risk cases and timely referral which has to be corrected upon.

All women required blood transfusion which is comparable to other studies hence emphasizing that peripartum hysterectomy is associated with extensive blood loss and need for transfusion. ${ }^{14} 96 \%$ of the women also required intensive care unit service due to haemodynamic instability, need for inotropic support or for mechanical ventilatory support.

There were three $(10.3 \%)$ maternal deaths after peripartum hysterectomy. In the literature, rates of maternal mortality from 0 to $17 \%$ have been reported. ${ }^{14,15}$ Hemorrhagic shock is the most common reason for maternal mortality. Majority of the women who underwent peripartum hysterectomy had still 
birth $(76 \%)$. There was no maternal or fetal death in the similar study conducted by Tadesse et $a{ }^{16}$ as the indication differed. Placental pathology being the most common indication as compared to our study where rupture uterus was the most common indication and it is obvious to salvage the fetus following rupture. The advent of modern blood banking, antibiotics, safe anaesthesia and advanced surgical technique was a major contributing factor in reducing maternal and fetal morbidity and mortality to a minimum in these set up.

Emergency peripartum hysterectomy is associated with intraoperative and postoperative complications. Engelsen et $\mathrm{al}^{17}$ reported a total of 34 complications in 11 women of which three women had postpartum psychiatric illness severe enough to require psychiatric counselling.

In our study, febrile morbidity was the most common complication (48\%) followed by respiratory tract infection and urinary tract infection. Two women developed acute kidney injury and one had pelvic abscess post operatively. Selo-oj et al in their study also reported febrile morbidity to be the most common post operative complication $(40 \%)$ in women who underwent peripartum hysterectomy. ${ }^{6}$

The mean duration of hospital stay in these women was $9 \pm 5.1$ days which was comparable to the study done by Sharma et al where mean length of hospitalisation was 10 days. ${ }^{18}$

\section{CONCLUSIONS}

Rupture uterus has been identified as the most common indication for peripartum hysterectomy; identification of high risk cases, proper antepartum and intrapartum care and timely referral can to some extent prevent this complication associated with delivery. Abnormal placentation which is on increasing trend due to increase in the rate of caesarean section should not be ignored upon. Prior identification of morbidly adherent placenta, delivery by skilled obstetrician and delivery in a set up with adequate blood product facility in the setting of obstetrical haemorrhage are some of the measures to prevent peripartum hysterectomy.

Disclosure : The author has no conflict of interest.

\section{REFERENCES}

1. Filippi V, Ronsmans C, Gandaho T, Graham W, Alihonou E, Santos P. Women's reports of severe (near-miss) obstetric complications in Benin. Stud Fam Plann. 2000;31:309-24.

2. Rossi AC, Lee RH, Chmait RH. Emergency postpartum hysterectomy for uncontrolled postpartum bleeding: A systematic review. Obstet Gynecol. 2010;115(3):637-44.

3. Chestnut DH, Eden RD, Gall SA, Parker RT. Peripartum hysterectomy: A review of cesarean and postpartum hysterectomy. Obstet Gynecol.1985;65:365-70

4. Clark SL, Yeh SY, Phelan JP, Bruce S, Paul RH Emergency hysterectomy for obstetric hemorrhage. Obstet Gynecol.1984;64:376-80.

5. Chisara CU, Paul AF, Charles AA. Peripartum hysterectomy in Aba southeastern Nigeria. Australian and New Zealand Journal of Obstetrics and Gynaecology. 2008;48:580-2.

6. Selo-Ojeme DO, Bhattacharjee P, Izuwa-Njoku NF, Kadir RA. Emergency peripartum hysterectomy in a tertiary London hospital. Arch Gynecol Obstet. 2005;271:154-9.

7. Wu S, Kocherginsky M, Hibbard JU. Abnormal placentation: Twenty-year analysis. Am J Obstet Gynecol. 2005;192:145861

8. Ezechi OC, Kalu BKE, Njokanma FO, Nwokoro CA, Okeke GC. Emergency peripartum hysterectomy in a Nigerian hospital: a 20-year review. Journal of Obstetrics and Gynaecology. 2004;24(4):372-3.

9. Kacmar J. Route of delivery as a risk factor for emergent peripartum hysterectomy: a case-control study. Am J Obstet Gynecol. 2003;102:141-5.

10. Forna F, Miles AM, Jamieson DJ. Emergency peripartum hysterectomy: a comparison of cesarean and postpartum hysterectomy. Am J Obstet Gynecol. 2004;190:1440-4.

11. Oguz Y, Ismail O ,Nese Y, As S. Emergency peripartum hysterectomy: a 9-year review. Arch Gynecol Obstet. $2006 ; 274: 84-7$

12. Stanco LM, Schrimmer DB, Paul RH, Mishell DR. Emergency peripartum hysterectomy and associated risk factors. Am J Obstet Gynecol. 1993;168:879-83

13. Kastner ES, Figueroa R, Garry D, Maulik D. Emergency peripartum hysterectomy: experience at a community teaching hospital. Obstet Gynecol. 2002;99:971-5

14. Zelop CM, Harlow BL, Frigoletto FD, Safon LE, Saltzman DH. Emergency peripartum hysterectomy. Am J Obstet Gynecol.1993;168:1443-8

15. Zeteroglu S, Ustun Y, Engin-Ustun Y, Sahin G, Kamaci M. Peripartum hysterectomy in a teaching hospital in the eastern region of Turkey. Eur J Obstet Gynecol Reprod Biol. 2005;120(1):57-62.

16. Tadesse W, Farah N, Hogan J, D’Arcy T, Kennelly M, Turner MJ. Peripartum hysterectomy in the first decade of the 21st century: Journal of Obstetrics and Gynaecology. 2011;31(4):320-1

17. Engelsen BE, Albrechtsen S, Iversen OE. Peripartum hysterectomy-incidence and maternal morbidity. Acta Obstet Gynecol Scand. 2001;80:409-12.

18. Sharma A, Farah R, Aziz AI. Journal of Obstetrics and Gynaecology. 2005;25(5):455-7. 